The Anthropocene event in social theory

On ways of problematizing nonhuman materiality differently

Blok, Anders; Jensen, Casper Bruun

Published in:

The Sociological Review

DOI:

10.1177/0038026119845551

Publication date:

2019

Document version

Peer reviewed version

Citation for published version (APA):

Blok, A., \& Jensen, C. B. (2019). The Anthropocene event in social theory: On ways of problematizing nonhuman materiality differently. The Sociological Review, 67(6), 1195-1211.

https://doi.org/10.1177/0038026119845551 
This paper (post-print) has been accepted for publication in The Sociological Review. Edited, revised and typeset version of this paper will be published in The Sociological Review, vol. 67(6) by Sage, All rights reserved. (c) Sage, 2019

\section{The Anthropocene Event in Social Theory: On Ways of Problematizing Non-Human Materiality Differently}

Anders Blok (Department of Sociology, University of Copenhagen - contact: abl@soc.ku.dk) \& Casper Bruun Jensen (Department of Anthropology, Osaka University)

\section{Abstract}

Signaling that 'humanity' has radically changed the Earth's environmental parameters, the Anthropocene currently generates debate across the socio-cultural sciences. In this context, neo-Marxist and new materialist approaches stand out for the way they oblige social theory to catch up with new material realities. We share the conviction that the Anthropocene might constitute a genuine event for social theory and practice. However, we argue that the search for alternative ways of problematizing and 'dramatizing' our eco-political predicament confronts these approaches with unresolved issues of scientism and economic totalization. Looking for another path, we turn to science and technology studies (STS), and especially actor-network theory (ANT). We relay the long-standing focus on nonhuman agency characteristic of this field via Isabelle Stengers' argument that we must "accept" the reality of Gaia's intrusion into collective historicity. The challenge posed by Stengers, we suggest, requires the development of an art of immanent attention to the politics of varied matters as they unfold across diverse ecologies of practice. Extending further than the present preoccupations of Euro-American social theory, other areas within and across environmental history, activism, and politics offer sites of resistance as well as experimentation whose conceptual possibilities and practical 
This paper (post-print) has been accepted for publication in The Sociological Review. Edited, revised and typeset version of this paper will be published in The Sociological Review, vol. 67(6) by Sage, All rights reserved. (c) Sage, 2019

efficacies have yet to be explored. Slowing down theory sufficiently to learn from these multiple sites, we argue, is the starting point for an approach more adequate to the problems posed by the Anthropocene event.

Keywords: Anthropocene; Gaia; new materialism; neo-Marxism; science and technology studies (STS)

This is exactly what I fear with the Anthropocene thesis; it proposes a 'future perfect continuous' tense, which puts theorists into a very agreeable position. The mess can now be forgotten, swallowed in a continuity that can be theorized in a single shot. Abysmal aporia will flourish, happily confronted by theoreticians hunting down shades of anthropocentrism in other theoreticians' writings (Isabelle Stengers, in conversation with Davis \& Turpin, $2013,178)$.

Ongoing ecological transformations and disruptions have long been matters of concern for the social sciences. In recent years, the Anthropocene has become the latest master narrative, operating as a clarion call across the natural and social sciences, and into the humanities. The concept places upon 'humanity' the burden of having radically changed the Earth's environmental parameters, to the point where several 'tipping points' may soon be breached with incalculable but likely catastrophic consequences for the future of the planet. Little wonder that this unprecedented situation has generated massive concern both in- and outside academia, along with calls for new modes of analysis as well as ever louder calls for urgent action (Castree, 2014). 
This paper (post-print) has been accepted for publication in The Sociological Review. Edited, revised and typeset version of this paper will be published in The Sociological Review, vol. 67(6) by Sage, All rights reserved. (c) Sage, 2019

In social theory, the Anthropocene has given rise to widely divergent interpretations and forms of problematization. ${ }^{1}$ Scholars inspired by eco-Marxism criticize the term for failing to address colonial and capitalist histories, proposing to speak instead of the 'Capitalocene' (Malm \& Hornborg, 2014; Moore, 2015). Others insist that the central question raised is how to deal with the unruly forces of the earth that now shape 'geosocial futures' (Clark \& Yusoff, 2017). Underlying this latter suggestion, a range of broadly 'new materialist' scholarship shares the conviction that the Anthropocene obliges socio-cultural analysts to 'catch up' with the nonhuman, and incorporate a radically material, possibly 'inhuman' (Clark, 2011) world into social theory (e.g. Coole \& Frost, 2010; Clark, 2014; Wark, 2015; Clark \& Yusoff, 2017).

Given the significance of anthropogenic climate change it is difficult to disagree with the general orientation of such arguments. Indeed, we also think that the current situation holds the potential to institute a genuine 'event' (Stengers, 2000) - in the sense that it may come to mark a decisive difference between a 'before' and an 'after' - for both the socio-cultural and the natural sciences. To characterize this event, we offer a detailed examination of new materialist and eco-Marxist approaches to the Anthropocene. We do so because both use the Anthropocene as a platform for developing arguments about novel obligations placed upon contemporary social theory, which are at once far-reaching and far from innocent.

Here we identify some unresolved issues. In the name of appreciating material agency, new materialist approaches struggle with legacies of scientism. Meanwhile,

\footnotetext{
${ }^{1}$ For a brief overview of the natural-scientific literature on the Anthropocene see (Rockström et al., 2009).
} 
This paper (post-print) has been accepted for publication in The Sociological Review. Edited, revised and typeset version of this paper will be published in The Sociological Review, vol. 67(6) by Sage, All rights reserved. (c) Sage, 2019

new eco-Marxist formulations have difficulties letting go of an impulse towards economic totalization characteristic of many strands of Marxism.

Probably due to our position as Science and Technology Studies (STS) scholars working with actor-network theory (ANT) and related ideas, we are particularly attentive to such kinds of problems. On the one hand, ANT's decade-long attempt to specify the conceptual and empirical possibilities of engaging nonhuman agency beyond scientism (e.g. Latour 1988, 2000, 2017) troubles the new materialist ambition to engage inhuman things in themselves. On the other hand, ANT-informed work on the material and pragmatic variability of markets challenges the eco-Marxist rendition of capitalism as the one overarching framework for making sense of ecological disruption (e.g. Callon 1998; Callon, Millo and Yuval 2007). Rather than sweeping these conceptual and methodological issues under the Anthropocene carpet and offering another eclectic combination of more or less incongruent ideassomething that happens with some frequency these days ${ }^{2}-$ we examine the different ways in which these approaches 'dramatize' (Stengers 2014) the problem of nonhuman materiality. The aim is to get a better handle on how social theorists might inhabit the Anthropocene event, including the question of whether the term itself is adequate for what it names.

In brief, and with a deliberate degree of provocation, we argue that an understanding of nonhuman agency informed by ANT entails something like a reversal of the interpretation of the relation between the Anthropocene and social theory put forth by new materialists and eco-Marxists. The present situation is not

\footnotetext{
2 The eclectic, and to a significant extent conceptually incongruent, use of social-theoretical tropes found in Bonneuil and Fressoz' (2016) The Shock of the Anthropocene is a case in point.
} 
This paper (post-print) has been accepted for publication in The Sociological Review. Edited, revised and typeset version of this paper will be published in The Sociological Review, vol. 67(6) by Sage, All rights reserved. (c) Sage, 2019

one in which socio-cultural studies need to 'catch up' with the natural sciences by learning to take nonhumans and materialities seriously. On the contrary, it is the natural sciences (and, belatedly, various theoretical formations within socio-cultural studies) that are finally beginning to catch up with the insight that societies and economies are fundamentally shaped by nonhuman agency. ${ }^{3}$ But our aim is not the petty one of vindicating ANT (or STS in general) against new competitors. Instead, we use new materialist calls for an intensified interest in material agency and ecoMarxist endeavors to rethink the relation between economies and ecologies as an entry-point for our own 'non-innocent' attempt to problematize the Anthropocene event differently. With this in mind, we turn to the figure of Gaia, which, due to the work of Isabelle Stengers and Bruno Latour, has recently re-emerged as an 'intellectually serious' figure for thinking through the implications of anthropogenic climate change (see Clarke 2017).

In contrast with the Anthropocene and its inversion, the Capitalocene, Isabelle Stengers' (2015a, 2015b, 2017) version of Gaia simultaneously highlights that humanity is in no position to either control or manage the earth; acknowledges that certain people and corporations are the main causes of Gaia's intrusion; and insists that the needed responses must be at once pragmatic and experimental. The implication is that, rather than placing the problem of response in the hands of scientists, politicians, businesses, or cutting-edge social theorists, it must be distributed across a heterogeneous ecology of practices.

\footnotetext{
${ }^{3}$ Before his premature death, the sociologist Ulrich Beck argued that the natural sciences were finally catching up with the social sciences via the Anthropocene event. We dedicate the point to him.
} 
This paper (post-print) has been accepted for publication in The Sociological Review. Edited, revised and typeset version of this paper will be published in The Sociological Review, vol. 67(6) by Sage, All rights reserved. (c) Sage, 2019

We begin by tracing the trajectories that led new materialists towards the Anthropocene, and eco-Marxists towards the Capitalocene. Subsequently, we explore the alternative problematization of the eco-political situation made available by Stengers' Gaia. As indicated, we believe that Gaia opens up a more capacious 'cosmopolitical' scenography; one that entails an experimental search for situated pathways towards the reinvention of numerous practices, including social theory.

\section{Pathways to matter: The new materialisms}

In the following sections, we examine two influential new materialist and eco-Marxist responses to the Anthropocene outlined, respectively, by the geographer Nigel Clark (2011, see also 2014, 2017) and the environmental historian Jason Moore (2015). We engage these two particular thinkers, since their ways of dramatizing the issues are interesting in their own right while also holding exemplary value, and because it is important to be specific rather than offering abstract diagnoses. However, we begin with some more general observations about new materialism, because its ideas and premises have significantly influenced current discussions about the Anthropocene in social and cultural theory.

In their introduction to the edited volume New Materialisms, Diana Coole and Samantha Frost argued that an adequately updated social theory entails a "reprisal of materialism" that must be "truly radical" $(2010,3)$. The "contemporary context", including the fact of climate change, they asserted, "demands a theoretical rapprochement with material realism" (6) on the basis of new developments in the natural sciences. In social and cultural theory, this would mean revisiting "the most fundamental questions about the nature of matter and the place of embodied humans within a natural world" (6). 
This paper (post-print) has been accepted for publication in The Sociological Review. Edited, revised and typeset version of this paper will be published in The Sociological Review, vol. 67(6) by Sage, All rights reserved. (c) Sage, 2019

The authors observed that previous materialist philosophers, including Marx, Nietzsche and Freud, had also been influenced by natural science (5). In the $21^{\text {st }}$ Century, however, the classical Newtonian paradigm that had inspired these thinkers has been obviated by newer developments and problems. Thus, a new materialism was needed, which would be: "resonant with, and to some extent informed by, developments in natural science" (6-7). For Coole and Frost, post-classical physics held special promise, since it had shown matter to be "more elusive" than previously expected, and to contain "an excess, force, vitality, relationality, or difference, that renders matter active, self-creative, productive, unpredictable" (9).

Coole and Frost were explicit that the new materialism would not entail an uncritical acceptance of scientific facts or theories, since "scientific theories cannot simply be imported into philosophy" (13). At the same time, they were equally emphatic that: "the tropes and rhythms they [scientific theories] suggest can transform theoretical discourses" (13). However, as their discussion turned towards the realm of sub-atomic particles and dark matter, the distinction between improper theoretical importation and inventive tropic-rhythmic transformation itself began to blur and darken. As they draw the conclusion that Marx and Nietzsche must be questioned, revamped or bypassed since they got their physics wrong, it certainly appears as if new materialism judges the quality of social science on the basis of theories directly imported from natural science.

An obvious question pertains to what exactly is gained by drawing on new scientific insights. Coole and Frost indicate that one crucial benefit is an improved understanding of matter, which they describe in terms of excess, relationality and difference, and with recognition of its activity, self-regeneration and unpredictability. In many ways this list of qualities looks appealing, even if it is rather abstract and 
This paper (post-print) has been accepted for publication in The Sociological Review. Edited, revised and typeset version of this paper will be published in The Sociological Review, vol. 67(6) by Sage, All rights reserved. (c) Sage, 2019

vague. Upon closer inspection, however, it quickly becomes evident that each of these terms is closely related to concepts that already have extensive histories in sociocultural theory. Thus, excess has long been affiliated with George Bataille, difference with Jacques Derrida and Gilles Deleuze, creativity with Henri Bergson, and relationality and unpredictability with nearly all social thought over the last half century. In other words, it is not altogether clear what it is the new materialism intends to 'radically change.'

Coole and Frost also made a number of methodological suggestions. Thus, they argued that to address climate change and global environmental devastation in sociocultural analysis requires sensitivity to the "resilience of matter," to the "importance of bodily experience" as well as to the "myriad interrelated material systems needed to sustain citizens" (29). Accordingly, they advocated a "multimodal methodology... congruent with multi-tiered ontologies" that "run between different levels of the social system and especially between the micro-level or everyday, and the macrolevel or structural" (29).

At this point, however, another objection to the claim to novelty suggests itself. After all, methodologies that move between scales of 'micro' and 'macro' is by no means a new idea. More importantly, actor-network theory (e.g. Callon and Latour 1981), feminist science studies (e.g. Haraway 2016), and anthropological approaches (e.g. Tsing 2012) have long challenged the assumption that scales are given. They have replaced this classic idea with an analytics that sees scales as emergent effects of heterogeneous interactions between humans and nonhumans (e.g. Jensen, 2007). Instead of slotting reality into fixed micro-, meso- and macro-scales, each dealing with appropriately delineated topics and operating according to their own principles, these are studies of how scales are constructed through socio-technical ordering 
This paper (post-print) has been accepted for publication in The Sociological Review. Edited, revised and typeset version of this paper will be published in The Sociological Review, vol. 67(6) by Sage, All rights reserved. (c) Sage, 2019

processes.

As this discussion suggests, despite its welcome insistence on material agency, new materialism contains various ambiguities and unresolved tensions, which makes it difficult to appraise its (new) capacities for dealing with the kinds of ecological transformations indexed by the Anthropocene. The following discussion of the geographer Nigel Clark's Inhuman Nature (2011) allows us to examine this question more carefully.

\section{An inhuman nature for Anthropocene social theory?}

Given the focus of the discipline, it is probably not very surprising that the most sustained application of new materialist ideas to the Anthropocene has occurred in geography. Along with Kathryn Yusoff (e.g. 2013) and others, Nigel Clark has shown particular commitment to demonstrate not only that humans now shape geology but also that social life is underwritten by geologic agency (Clark, 2014, 2017). Here, we focus specifically on his Inhuman Nature, which presents a detailed argument for a broad expansion, both speculative and empirical, of the role of the nonhuman in social theory.

To develop this argument, Clark combines elements from new materialism and the philosophical approach known as object-oriented ontology. As regards the former, Clark $(2011,44)$ refers to a series of thinkers, including Elizabeth Grosz, Vicki Kirby and Myra Hird, all of whom insist that the biological and "inorganic systems that sustain life" also enable and 'provoke' human culture. Thus, Grosz refers to nature as 'the ground' out of which life emerges and Kirby wants to reclaim nature from those who "would reduce nature or the ground to some kind of culturallinguistic effect" (44). Clark complements these ideas with the speculative 
This paper (post-print) has been accepted for publication in The Sociological Review. Edited, revised and typeset version of this paper will be published in The Sociological Review, vol. 67(6) by Sage, All rights reserved. (c) Sage, 2019

philosopher Quentin Meilassoux's (2008) critique of 'correlationism', a term used to designate any post-Kantian philosophy skeptical of the possibility of reaching 'things in themselves.'

Similar to Coole and Frost, Clark reassures those who might worry about his use of scientific claims:

It is, of course, crucial for social scientists to maintain a critical attitude towards the premises, practices and products of the physical sciences. We know this well enough by now that it need not be rehearsed at every meeting or reading (xviii)

Also similar to Coole and Frost, he is explicit that his own

argument depends utterly on the 'substantive' findings of the earth sciences and on the recent philosophical re-activation of the question of 'things-inthemselves' (xiv)

The re-occurrence of this double gesture, which simultaneously acknowledges and side-steps the problem of scientism can be seen as testimony to the real difficulties social scientists face as they try to activate material agency. And in Clark's case, too, it is quite hard to see how 'utter dependence' on the substantive findings of the earth sciences squares with a sustained and critical interrogation of the "premises, practices and products of the physical sciences."

Clark cites with approval the philosopher Ray Brassier's claim that "fully mind-independent realities"—of plate tectonics, undiscovered oil reserves, the accretion of the earth—“are found across multitudes of times, spaces, scales or fields 
This paper (post-print) has been accepted for publication in The Sociological Review. Edited, revised and typeset version of this paper will be published in The Sociological Review, vol. 67(6) by Sage, All rights reserved. (c) Sage, 2019

of existence" (48). Yet, if we pause to ask from whence comes the certainty of these 'fully mind-independent' facts about "autonomous, human-independent realities" (48), the answer is clearly that they come with the unquestioned authority of scientists. It is because the genesis of scientific facts (Fleck, 1979 [1935]) is not subject to scrutiny that it becomes possible to conceive of them as fully mind-independent. ${ }^{4}$

One finds in the work of Deleuze and Guattari-a source of inspiration for actor-network theory (ANT) as well as strands of new materialism (e.g. Coole and Frost, 2010, 9) and Clark's (2017) recent work on the Anthropocene-quite a different approach to scientific concepts. Felix Guattari $(1989,131)$ wrote that "there is an urgent need for us to free ourselves of scientistic references and metaphors: to forge new paradigms which are instead ethicoaesthetic in inspiration." Guattari's point was obviously not that either science or matter does not matter. Instead, he highlighted that the creative evolution of different fields and disciplines has to be open to divergence. Thus, each practice will have to invent its own situated modes of attention and response to ecological transformations. As we highlight later, this is also the case for the socio-cultural sciences.

\section{From inhuman nature and (back) to entangled worlds}

Nigel Clark (2011) is sympathetic to Bruno Latour's long-standing effort to grant nonhumans a role in socio-cultural analysis. At the same time, in line with Coole and Frost's demand for a 'truly radical' reappraisal of materialism, he is critical of what he perceives as ANT's insufficient radicalness.

Constitutively hybrid, Latourian actor-networks are composed of a mixture of

\footnotetext{
${ }^{4}$ See Abrahamson et. al. (2015) for related comments on Jane Bennett's influential version of new materialism.
} 
This paper (post-print) has been accepted for publication in The Sociological Review. Edited, revised and typeset version of this paper will be published in The Sociological Review, vol. 67(6) by Sage, All rights reserved. (c) Sage, 2019

human and nonhuman entities. If one searches for an ultimately inhuman nature this becomes a problem, since-as Clark $(2011,37)$ notes with reference to Graham Harman—one can find in Latour only "the most flickering hints of networks devoid of human involvement." Moreover, since ANT insists that to speak of or for others implies mediation and translation, "it is hard to imagine how a domain fully independent of the human can legitimately receive attention as anything more than an abstract possibility" (37). Because actor-networks fail to follow through on the "beautiful and profound idea of nonhumans composing fully autonomous worlds of their own", Clark finds them prosaic and "strangely conventional" (213).

On this point he distinguishes sharply between Bruno Latour and Isabelle Stengers whose work on Gaia is crucial for us in what follows. While Latour is described as unable to "concede" the potency of things, and thus ends up a closet correlationist, Clark sees Stengers as keenly attentive to the inhuman. Contrary to "many of her fellow science studies scholars,"5 he writes (38), "who emphasize the human-nonhuman co-construction of climate", Stengers:

drives home the point that issues of global ecological transformation... encourages us to conceive of the planet not just in terms of our own interchanges with it, but in and for itself: "Of the Earth, the present subject of our scenarios, we can presuppose a single thing: it doesn't care about the questions we ask about it" (Stengers, 2000, 145; cited by Clark, 2011, 38).

\footnotetext{
${ }^{5}$ Clark does not identify any of these researchers. Stengers is a philosopher of science rather than an STS scholar.
} 
This paper (post-print) has been accepted for publication in The Sociological Review. Edited, revised and typeset version of this paper will be published in The Sociological Review, vol. 67(6) by Sage, All rights reserved. (c) Sage, 2019

In fact, it is unlikely that most STS scholars-certainly those working in the tradition of ANT — would disagree. This includes Latour, who began his Irreductions $(1988,193)$ with the following comments:

Things-in-themselves? But they are fine, thank you very much. And how are you?... The tree shows what it can do, and as it does so, it discovers what all the other forces it welcomed can do. You laugh because I attribute too much cunning to it? Because you can fell it in five minutes with a chain saw? But don't laugh too soon... Soon you may have no more fuel for your saw. Then the tree with its carboniferous allies may be able to sap your strength. So far it has neither lost nor won, for each defines the game and time span in which its gain or loss is to be measured.

As this quote suggests, the difference between ANT and Clark's new materialism is hardly found in the latter's more profound appreciation of nonhuman existence. It pertains, rather, to the possibility of gaining a hold on such existence without mediation, for example by scientists, their instruments and laboratories.

On this point, however, there are important differences. They can be brought out by tracing Clark's (2011, p.38) interpretation of Stengers' (2000, p.128) observation that "[e]verything changes when one leaves the laboratory" as support for his notion of an inhuman nature.

On the one hand, Stengers is indicating that outside the circumscribed space of the laboratory, nonhuman forces cannot easily be controlled. On the outside, she writes, "one finds friction, wind, the irregularity of soil, and the density of milieus" (2000, p.128). Yet, on the other hand, this has little to do with a commitment to 'fully 
This paper (post-print) has been accepted for publication in The Sociological Review. Edited, revised and typeset version of this paper will be published in The Sociological Review, vol. 67(6) by Sage, All rights reserved. (c) Sage, 2019

mind-independent' things. What Stengers is addressing is rather the impossibility of maintaining a strict separation between scientific facts and cultural fictions outside the space of the laboratory. As vividly exemplified by ecological controversies, on the outside it does indeed become very difficult for scientists to control the situation by referring to objective facts. But this means that it becomes correspondingly harder to identify any pure and untainted testimony to an inhuman nature.

Significantly, Clark neglects to follow Stengers' paragraph to the end. After invoking the wind, friction, and the irregularity of soil, she continues:

And one also finds a world acted on by other actors, pursuing other projects [...]. With regard to these actors, the scientist conscious of changing milieus could ask himself: "Why am I so interesting to them? Where are all the others, who are capable of taking into account everything that my laboratory must eliminate in order to authorize me to speak?" (2000, p.128)

In the end, then, Stengers' concern has nothing to do with trying to access a world indifferent to the plight of humans. Instead, her problem, similar to Latour's (e.g. 2004), is how to extend the scientific event without obliterating all the 'correlations' that make others-whether humans or nonhumans-act.

It follows that the problem is not really one of correlation at all. Instead, the extension of an event is defined by the capacity of new elements-here scientific facts, objects or concerns - to insert themselves in other practices in ways that, by modifying existing relations, generates consequential new kinds of interest. Equidistant from vindicating the idea of a totally external nature and from submitting to human correlations, scientific objects are thus exhibited as gaining or losing 
This paper (post-print) has been accepted for publication in The Sociological Review. Edited, revised and typeset version of this paper will be published in The Sociological Review, vol. 67(6) by Sage, All rights reserved. (C Sage, 2019

existence through processes of mediation and transformation that stretch into varied ecologies of practice (Stengers, 2005). Rather than complying with the dictates of science, these practices further add to and complicate the question of consequences.

In turn, this is why the unfolding planetary event, which Stengers (2015b) calls the intrusion of Gaia, is indeterminate-like all events-except by its effects and "the problem posed in the future it creates" (Stengers, 2000, p.66). Gaia can be identified neither with the Anthropocene nor with the Capitalocene (discussed further below), because both, in their different ways, over-determine the situation and foreclose the possibility of staging the problem differently. What is at issue is elucidation of the varied entanglements of people and diverse earthly powers.

In appreciation of the event's indeterminacy, Gaia is measured by the multiplicity of its interpretations and effects. Once one leaves the scientific laboratory, Stengers thus urges us to ask: where are all the others, capable of taking into account what the laboratory itself could not? Today, climate and earth scientists are themselves posing such questions - both to socio-cultural scholars and to wider publics (see Stengers, 2015a). Indeed, Nigel Clark (2017) has also recently begun to ask such questions with reference to earth systems governance (without, in our view, taking full consideration of everything entailed by this question).

Considering the rhetorical energy spent on differentiating his inhuman approach from Latour's 'strangely conventional' analyses, we might expect Clark's own analyses to look altogether different. Like in the case of Coole and Frost, however, it turns out to be difficult to show just how, why, and to whom the attention to radically inhuman matters should matter. The problem is that, as a social scientist, Clark is still obliged to deal with people and their situations.

After spending many pages demolishing Latour's residual anthropocentrism- 
This paper (post-print) has been accepted for publication in The Sociological Review. Edited, revised and typeset version of this paper will be published in The Sociological Review, vol. 67(6) by Sage, All rights reserved. (C Sage, 2019

"hunting down shades of anthropocentrism," as Stengers wrote in our introductory quote-he eventually turns to Emmanuel Levinas to develop an analysis of sociality and hospitality in the wake of environmental catastrophe (193ff). Rather than entering the 'beautiful and profound' realm of fully autonomous non-human worlds, we find ourselves amidst many socio-cultural relations, organizations, politicians, scientists and other people who make sense of disaster and respond to it.

In the end, the notion of inhuman nature functions mainly as a persistent reminder that floods, fires, and storms do indeed occur and that they do affect people in multiple ways. The insight is important and very difficult to disagree with. It is difficult, however, to see this way of problematizing nonhumans in the Anthropocene as adding something particularly radical or new to social theory.

\section{Updating Marx for the Capitalocene}

If the central preoccupation of Clark, the geographer, was to activate the earth's geological powers against anthropocentric views that ascribe all agency to people, a core interest of resurgent eco-Marxism(s) is to locate ecological transformations in the context of capitalist history.

Marx himself grew increasingly interested in natural science as he developed a theory of the 'metabolism' of Man and Nature and the (alienated) labor-induced 'metabolic rift' of capitalist exploitation of natural resources (Wark, 2015). Moreover, like much of the Western Marxist canon, eco-Marxism is typically committed to the possibility of characterizing the 'true', 'underlying', 'systemic' or 'total' view of SocioNatural Reality. In this sense, much eco-Marxism assumes what the philosopher Graham Harman (2015) dubs a 'truth politics' that, to varying degrees, extends scientism from the natural and into the socio-cultural sciences. One case in point is 
This paper (post-print) has been accepted for publication in The Sociological Review. Edited, revised and typeset version of this paper will be published in The Sociological Review, vol. 67(6) by Sage, All rights reserved. (c) Sage, 2019

the way the Anthropocene has transformed into the "Capitalocene."

The Capitalocene has been given a range of interpretations by quite a heterogeneous group of scholars. The political ecologists Andreas Malm and Alf Hornborg (2014) deploy the term as part of a frontal critique of the 'species concept' of the Anthropocene. By locating agency at the level of the human species, they charge, Anthropocene scholarship fails to analyze the 'vested interests' of capitalism as the historical agent of inequality and exploitation all over the planet. Meanwhile, the feminist science studies scholar Donna Haraway (2016) uses the Capitalocene as a stepping-stone towards a de-centered call for attending to 'kinships' across human and non-human worlds. ${ }^{6}$ Mediating between these positions is the environmental historian Jason W. Moore's highly regarded Capitalism in the Web of Life (2015).

In a way, Capitalism in the Web of Life occupies a position resembling that of Nigel Clark's Inhuman Nature, except that its starting point is eco-Marxist rather than new materialist. In lieu of Clark's mixture of new materialism and object-oriented ontology, Moore seeks a radical undoing of any nostalgic vestiges of Society-Nature dualism, which is depicted as preventing earlier forms of (eco-)Marxism from fully critiquing present-day environmental crises.

In a nutshell, Moore develops an analysis of capitalism as working in and through nature, rather than being located on its 'outside.' Conceived as a form of power-laden 'environment-making' (Moore, 2015, p.45ff), this world-ecological perspective thinks capital and capitalism beyond Society-Nature dualism through the notion of the oikeios, "the creative, historical, and dialectical relation between, and also always within, human and extra-human natures" (35). As a 'multilayered

\footnotetext{
${ }^{6}$ It is a stepping-stone because Haraway develops yet another concept, 'the Chthulucene'. This concept bears family resemblance to Stengers' Gaia, which holds our attention below.
} 
This paper (post-print) has been accepted for publication in The Sociological Review. Edited, revised and typeset version of this paper will be published in The Sociological Review, vol. 67(6) by Sage, All rights reserved. (c) Sage, 2019

dialectic,' the oikeios comprises flora and fauna, but also the planet's manifold geological and biospheric processes, as these gets 'bundled' up with forms of 'social' organization. Moore thus sees historical agency as an emergent property of "configurations of human activity with the rest of life."

The question of alterity; or, how to undo economic totalization?

Reading Capitalism in the Web of Life, it is striking to observe how close Moore's project might have been to what he dismissively characterizes as 'cultural studies' that "highlight hybrids, assemblages, and networks" (33) (in a word, ANT and its relatives). Yet, even as Moore (48) rhetorically asks whether "anyone today seriously doubt that diseases, or climates, or plants make history as much as any empire?", and although his answer in some ways resembles those given by Latour, Haraway, Stengers or Anna Tsing (2015), his own examination of these more-than-human connections proceeds via the Marxist canon. ${ }^{7}$

Moore wants to rethink capital as a form of human-and-natural accumulation, which has achieved global hegemony since the $16^{\text {th }}$ century due to the accessibility of 'cheap nature' — of food, labor-power, energy, and raw materials-for which capital always pays too little (119). Latter-day ecological crises, however, signal that capital is running out of cheap nature to extract. In the end, therefore, much hinges on the conceptual boundary between capital and its 'outside', or alterity. But this is where things get tricky. As noted, Moore rejects the idea of a pre-capitalist, pristine, or unspoiled Nature, emphasizing instead historically and geographically specific projects of capitalization, wrought within shifting relations of power. In this analysis,

\footnotetext{
${ }^{7}$ Even so, we agree with McKenzie Wark $(2015,129)$ that Marxism must be seen "as a heterogeneous collection of rhetorics, theories, methods, results."
} 
This paper (post-print) has been accepted for publication in The Sociological Review. Edited, revised and typeset version of this paper will be published in The Sociological Review, vol. 67(6) by Sage, All rights reserved. (c) Sage, 2019

cheap nature emerges as a dialectics of contingent-but-powerful capitalist strategies that run up against their own unforeseen consequences.

This conceptual maneuver, however, raises the question of whether it is actually possible to conceive of any outside to capitalism, or whether it fully encompasses the whole 'web of life'. The question is important because, as Dipesh Chakrabarty (2017) has written in response to his eco-Marxist critics (Malm and Hornborg, 2014), the existence of unequal global capitalism in general offers no specific conceptual handle on humanity's long-term ecological overshoot. However, even if Capitalism cannot operate as a master concept in the Anthropocene, Chakrabarty (2017) insists, this does not mean that it must be replaced with the human species as a successor concept. Instead, it is the very idea of master concepts that needs to go. Analogously, we suggest that the Anthropocene requires the development of concepts and forms of analysis that make it possible to keep very heterogeneous empirical settings and forms of conceptualization in simultaneous view (a point to which we return in discussing Stengers' Gaia).

The problem with Capitalism as an encompassing analytical category is well exemplified in Moore's analysis of the spread of and resistance to the 'cheap nature' of genetically modified crops (GMOs). In Moore's reading (2015, 270ff), GMO crops, attendant "super-weeds," and their intensified agro-chemical "taming cycle" primarily demonstrates the speed-up, "time-space compressed" dynamics through which increasingly globalized environments, stretching from the United States (US) to the global South, become part of "the system." Moore, however, has little to say about the importance of (supra-) nation-state projects and the varied interests and ideologies of the US and Europe (e.g. Stengers, 2015b; 2017, 390). Indeed, he dismisses the environmental movement in general, indicating that it has basically achieved nothing 
This paper (post-print) has been accepted for publication in The Sociological Review. Edited, revised and typeset version of this paper will be published in The Sociological Review, vol. 67(6) by Sage, All rights reserved. (C Sage, 2019

but a shift of production costs from the global North to the global South (228). With this gesture, the fierce contestations over capitalist projects across the global South, from justice-oriented social reformers, environmental activists, indigenous groups and others (e.g. de la Cadena, 2015) are discarded as ephemeral and more or less irrelevant.

At the same time, Moore assigns to nonhumans the severely circumscribed role as 'reserve energy' for capital, thus disregarding their agency and unruliness, not to mention their unpredictable political effects (e.g. Jensen, 2015). While Moore's analyses of agro-industrial projects appear resonant with Anna Tsing's (2015) morethan-human ethnography of capitalist frontiers and ruined landscapes, for example, he bestows no recognition on the unruliness of non-humans, like bacteria and fungi, which Tsing shows to have constantly troubled the strategies of plantation capitalism (cf. Stengers, 2017, 388).

In short, if the problem with Clark's new materialism was that no matter how hard he tried to evacuate people from inhuman nature they kept slipping in, the reverse trouble with Moore's eco-Marxism is that even as he tries to find ways of letting non-human, non-capitalist otherness into his analysis, his analytics continuously squeezes it out.

Even so, Moore's depiction of capital as a patterned set of historical and power-inflected projects that simultaneously de-valorizes nature and exceeds capitalist aims is interesting. Among other things, it shares critical intent if not conceptual orientation with Stengers' cosmo-political attempt to resist capitalism's eco-political irresponsibility in the face of Gaia's intrusion (Stengers, 2015b; see also Clarke, 2017, 6ff, and discussion below). The import and stakes of these analyses are captured by Haraway $(2016,48)$ who writes that to think the Anthropocene well: 
This paper (post-print) has been accepted for publication in The Sociological Review. Edited, revised and typeset version of this paper will be published in The Sociological Review, vol. 67(6) by Sage, All rights reserved. (C) Sage, 2019

one must surely tell of the networks of sugar, precious metals, plantations, indigenous genocides, and slavery, with their labor innovations and relocations and recompositions of critters and things sweeping up both human and nonhuman workers of all kinds.

The question, therefore, is how to recognize the brutal efficacy of capital while also noticing its many gaps and interstices, and while also paying attention to the fragile articulation of global capital with all sorts of other political matters, including unruly nonhumans. How, we might ask with Philippe Pignarre and Isabelle Stengers (2011), is it possible to inherit Marx's pragmatic impulse of anti-capitalist struggle while eschewing theoretical tendencies towards economic totalization?

Taken as a general program for rethinking social theory after the Anthropocene event, Moore's world-ecological Marxism seems to us less than fully convincing. Among other things, the failure to accord much conceptual and practical significance to science, culture, or even politics is troublesome, not least in light of the important observation that 'cheap nature' may be coming to an end. If anything, discourses of the Anthropocene have served to stake out limits for and resistances to the spread of capital's projects, through socio-cultural thinking, activist mobilizations, and localized struggles that deserve more attention (e.g. Beck, 1992; Latour, 2004; Jensen \& Blok, 2013; Jensen, 2015).

Despite its undeniable innovativeness, Moore's eco-Marxist approach is thus ultimately unable to carry through the important task of thinking the limits and vulnerabilities of capital. The very notion of Capitalocene, we sense, signals the difficulty of detecting what may be truly novel and radical about our current eco- 
This paper (post-print) has been accepted for publication in The Sociological Review. Edited, revised and typeset version of this paper will be published in The Sociological Review, vol. 67(6) by Sage, All rights reserved. (c) Sage, 2019

political predicament (see Latour, 2017).

Accordingly, we feel encouraged to search for supplementary or alternative ways of problematizing the Anthropocene event. We initiate this by tracing the trajectory of STS and ANT, currently prolonged and recast by Isabelle Stengers (2015a), who insists that we "accept the reality of Gaia."

\section{The Intrusion of Gaia: an alternative scenography}

In our view, the "intellectually serious extra-scientific figures of Gaia" (Clarke, 2017, 2) forged in these years in part by Bruno Latour (2017)—and intensified and redirected, in important ways, by Isabelle Stengers (2015a, 2015b, 2017) and by Deborah Danowski and Eduardo Viveiros de Castro (2017)_offer particularly promising ways of coming to terms with current eco-political events. ${ }^{8}$ Among these, Stengers' work stands out for the radical challenge it poses to a social theory bent on fully addressing these realities; challenges which, we affirm, also push back both at established ANT conventions and at Latour's kindred take on the geo-politics of Gaia. ${ }^{9}$

The crux of Stengers' (2015a) cosmo-political proposition for the present times is that, in the face of multiple environmental crises, we must come to 'accept' the reality of Gaia both intellectually and politically. What meaning does this proposition hold? A term of multiple origins, Gaia was a primordial deity in Greek mythology long before it was adopted in the 1960s by the chemist James Lovelock

\footnotetext{
${ }^{8}$ One important manifestation of this wider set of dialogues was the September 2014 Rio de Janeiro colloquium on The Thousand Names of Gaia. Bruno Latour and Donna Haraway presented, and Stengers' contribution was central to the discussions. See Danowski and Viveiros de Castro (2017).

${ }^{9}$ Space prevents us from exploring these overlaps and differences. See Clarke (2017) for a useful first step. Suffice to say that, in our reading, Stengers' attention to tropes of intrusion and resistance gives to her Gaia a poignant 'cosmo-political' urgency not as readily detectable in Latour.
} 
This paper (post-print) has been accepted for publication in The Sociological Review. Edited, revised and typeset version of this paper will be published in The Sociological Review, vol. 67(6) by Sage, All rights reserved. (C Sage, 2019

and the microbiologist Lynn Margulis to name the hypothesis of Earth as a complex, self-regulating system (see Clarke, 2017). As Stengers notes (2015a, 134), however, the term has since been re-incarnated in many guises, including in New Age mysticism and non-mainstream climate science, making it a "bastard child of climate sciences and ancient paganism." Far from being compromised by this legacy, however, Stengers sees Gaia's constitutive hybridity and indeterminacy as generative of its conceptual potential, since it protects the term from being captured by master tropes of any kind-scientistic, capitalist, or otherwise. The effect is to leave open the question of what exactly current events entail, placed among a multiplicity of divergent-yet-potentially-allied practices, as they attune, each in their different way, to the problematics of Gaia.

Signifying neither the conventional figure of Nature or the Earth, Stengers' Gaia is rather the name for a new, ominous being with its own regime of activity and sensitivity. At once hyper-responsive to (some) human actions, and unpredictable in response, she refers to Gaia as 'ticklish' (2015b, 47). Unfortunately, even as these 'ticklish' reactions may well prove deadly to humankind, Gaia is also 'indifferent' to our concerns. Contrary to theaters of political adjudication, where people have a chance to justify their actions, accepting the reality of Gaia means accepting that we are now living in a realm of non-negotiable yet largely indeterminate demands, and that if we fail to respond adequately, our cries will not be heard.

This is why Stengers (2015b) defines Gaia as an 'intrusion' into collective historicity, to which everyone, social theorists included, will have to learn to respond. Stengers figures the response in terms of a cosmo-political 'slowing down' of reasoning, which has multiple implications for how socio-cultural analysis might seek to inherit and transform the Anthropocene event. 
This paper (post-print) has been accepted for publication in The Sociological Review. Edited, revised and typeset version of this paper will be published in The Sociological Review, vol. 67(6) by Sage, All rights reserved. (c) Sage, 2019

Given Gaia's indifference to human pleas, it is indeed possible to speak of an asymmetric relation to a new 'ground', of the kind that held Clark's $(2011,2014)$ attention. For Stengers, however, Gaia does not designate a set of inhuman materials forming autonomous worlds. Quite differently, it operates as a speculative concept constructed to induce new appetites for thinking and acting among entangled practices. Noticeably, therefore, Stengers' key questions concern what accepting the reality of Gaia would mean for and demand from us (an 'us' that includes social theorists). At the same time, however, she insists that Gaia's demands must now be assumed to be a permanent feature of the world. Humans, therefore, will be answerable to Gaia for good. Accordingly, Gaia names an unprecedented form of 'mundane' transcendence (Clarke, 2017, 7), deprived of any guarantees. In this precise sense, Gaia's intrusion into historicity marks an irreversible event.

According to Stengers (2015b, 44ff), Gaia's hybrid genealogy is particularly useful because it obliges social theorists to scrutinize shifts inside and outside the natural sciences with equal care. What this underscores is the importance of simultaneously analyzing the transformations Gaia undergoes in the hands of different scientific disciplines and in the broader ecology of economic, political and cultural practices, across widely divergent settings. Making clear that there is no given hierarchy between scientific and other forms of knowledge, Stengers (ibid.) argues that Gaia offers a way of resisting "the temptation of brutally opposing the sciences against the reputedly 'nonscientific' knowledges." At issue, instead, is the "necessity of inventing" new ways of 'coupling' divergent forms of knowledge and practice.

Accordingly, Gaia's intrusion signifies a situation of radically indeterminate socio-natural practice, inquiry and politics. Importantly, this is not the uncertainty 
This paper (post-print) has been accepted for publication in The Sociological Review. Edited, revised and typeset version of this paper will be published in The Sociological Review, vol. 67(6) by Sage, All rights reserved. (C Sage, 2019

beloved by climate skeptics, since Gaia in its present state was produced by anthropogenic climate change. Instead, it is an indeterminacy that infiltrates science, culture, politics, economics and civic action at the level of practice, as no one can legitimately claim to know beyond any doubt how to adequately respond. Since sociocultural scholars are in no better position than their natural science colleagues to claim an extant position from which to capture the total implications of Gaia, a social theory troubled by its intrusion requires a far-reaching reconsideration of inherited concepts and modes of research.

By resituating 'capitalist sorcery' within a non-totalized scenography of forgotten legacies, collective resistances, mutual learning and civic experiments in living differently, Pignarre and Stengers (2011) have taken steps towards such a reconstruction. Similarly, Stengers (2015b) has re-described the European GMO resistance as a process that forged new alliances among concerned scientists, environmental activists and capable lay publics. These examples are indicative of the kinds of knowledge-making and civic-political learning processes now needed in response to the incapacities and cynicism of technocratic political elites.

In this novel situation, Stengers (2015b) thus insists on the importance of social-theoretical experimentation, understood as an ongoing effort to learn from other interested and inventive actors how to collectively resist the probability of a "coming barbarism." She calls for a situated and non-foundational practice of sociocultural inquiry that would take into consideration, and be responsive to, a range of divergent but allied knowledges and practices: natural-scientific, activist-public and otherwise.

Since the 1960s, environmental history, activism, and politics across all continents have generated a wealth of novel practices, the conceptual importance and 
This paper (post-print) has been accepted for publication in The Sociological Review. Edited, revised and typeset version of this paper will be published in The Sociological Review, vol. 67(6) by Sage, All rights reserved. (c) Sage, 2019

pragmatic efficacy of which is partly exhibited, yet far from exhausted, in social theory (see Jensen, 2015). Should trees have legal standing? (Stone, 1972). Might Earth-beings be ascribed constitutional rights? (de la Cadena, 2015). Can Japanese Shinto practices re-enchant the capacities of nonhumans? (Jensen \& Blok, 2013). How to care for and live respectfully in a more-than-human world of charismatic animals (Blok, 2011) and travelling, sprawling fungi (Tsing, 2015)? Can Gaia help break the long legacy of Euro-centrism in social theory, making it sensitive to other histories? (Danowski and Viveiros de Castro, 2017). Obviously, the questions raised are legion and no ready-made answers are lying around. Precisely: they are waiting to be invented and given conceptual shape by creative scholars in the socio-cultural sciences in conjunction with heterogeneous practitioners everywhere.

Addressing such questions therefore depends on a genuine willingness to put inherited socio-theoretical certainties at risk. This entails a reconfiguration of social theory in the image of what Deleuze and Guattari $(1987,372 \mathrm{f})$ called the 'following sciences', defined by a focus on empirical and conceptual variations and singularities and by locating natural and socio-cultural research in the world, and operating alongside a multiplicity of other co-inquirers (Jensen, 2012; Savransky, 2016). Were such a reconfiguration to succeed-unlikely as it seems - the Anthropocene might indeed become a re-generative event for social theory.

\section{Conclusion: Experimenting with matters in social theory}

After the Anthropocene event, it seems clearer than ever that "theory is always a detour on the way to something more important" (Stuart Hall, quoted in Wark, 2015, 7). Yet determining which kind of detour Anthropocene theory is going to be and where it is going to lead, depends on what one makes of theory and of its many 
This paper (post-print) has been accepted for publication in The Sociological Review. Edited, revised and typeset version of this paper will be published in The Sociological Review, vol. 67(6) by Sage, All rights reserved. (c) Sage, 2019

entanglements. Hall's statement must then be complemented with Donna Haraway's $(2016,12)$ insistence that "[i]t matters what matters we use to think other matters with."

As we have seen, the Anthropocene has given rise to calls for new approaches to social theory, and also to some claims to have already delivered them, not least by way of refiguring nonhuman agency and lively matter. It is probably not coincidental that the rush to create new theory for the Anthropocene, and the "agreeable position" in which, according to Isabelle Stengers, this demand places the theorists, has led to the elision of already existing ones. This is not to say that ANT, or STS in general, provides any off-the-shelf solution either. Nevertheless, the sensitivity of STS to the problems of scientism and economic totalization is helpful in opening up the sociocultural sciences to alternative ways of engaging the Anthropocene event. We have suggested that Stengers' dramatization of the problem in terms of accepting the reality of Gaia's intrusion offers a particularly fruitful extension of this legacy—one that entails a serious rethinking not only of the notion of the Anthropocene but also of its mirror image, the Capitalocene.

Taking this intrusion seriously, we suggest, requires the development of an art of immanent attention to the politics of varied matters as they unfold across the whole ecology of practices. Well beyond the present preoccupations of EuroAmerican social theory, environmental history, activism and politics are all full of sites of resistance and experimentation, the political potentials and conceptual capacities of which are far from exhausted. Slowing down theory sufficiently to learn from these multiple sites is the starting point for an approach adequate to the problems posed by the Anthropocene event, and an irritable, ticklish Gaia.

Inasmuch as it matters for social theory to continue to learn to expand its 
This paper (post-print) has been accepted for publication in The Sociological Review. Edited, revised and typeset version of this paper will be published in The Sociological Review, vol. 67(6) by Sage, All rights reserved. (c) Sage, 2019

modes of attentiveness to nonhuman materialities, one can certainly do worse than detour through the new materialists and eco-Marxists. However, any adequate responses to Gaia's intrusion must be based on an equally firm commitment to following, learning to be affected by, and experimenting with the many divergent knowledges and practices of natural science, environmental activism, and concerned publics currently emerging around the planet.

\section{Funding statement}

This research received no specific grant from any funding agency in the public, commercial, or not-for-profit sectors.

\section{References}

Abrahamsson, S.; Bertoni, F.; Mol, A.; \& Martin, R. I. (2015). Living with Omega-3: New Materialism and Enduring Concerns. Environment and Planning D, 33(1), 4-19.

Beck, U. (1992). Risk society: Towards a new modernity. London: SAGE Publications.

Blok, A. (2011). War of the whales: Post-sovereign science and agonistic cosmopolitics in Japanese-global whaling assemblages. Science, Technology \& Human Values, 36(1), 55-81.

Bonneuil, C., \& Fressoz, J.-B. (2016). The shock of the Anthropocene: The earth, history and us. London: Verso.

Callon, M. (Ed.) (1998). The laws of the market. Oxford, Blackwell Publishers. 
This paper (post-print) has been accepted for publication in The Sociological Review. Edited, revised and typeset version of this paper will be published in The Sociological Review, vol. 67(6) by Sage, All rights reserved. (c) Sage, 2019

Callon, M., \& Latour, B. (1981). Unscrewing the big Leviathan: How actors macrostructure reality and how sociologists help them do so. In K. Knorr-Cetina \& A. Cicourel (Eds.), Advances in social theory and methodology: Toward an integration of micro- and macro-sociologies (pp. 277-303). London: Routledge and Kegan Paul.

Callon, M.; Millo, Y.; \& Muniesa, F. (Eds.) (2007). Market devices. Malden, MA \& Oxford, Blackwell.

Castree, N. (2014). The anthropocene and geography I: The back story. Geography Compass, 8(7), 436-449.

Chakrabarty, D. (2017). The politics of climate change is more than the politics of capitalism. Theory, Culture \& Society, 34(2-3), 25-37.

Clark, N. (2011). Inhuman nature: Sociable life on a dynamic planet. Los Angeles, London, New Delhi, Singapore \& Washington DC: Sage.

Clark, N. (2014). Geo-politics and the disaster of the Anthropocene. The Sociological Review, 62(S1), 19-37.

Clark, N. (2017). Politics of strata. Theory, Culture \& Society, 34(2-3), 211-231.

Clark, N., \& Yusoff, K. (2017). Geosocial formations and the Anthropocene. Theory, Culture \& Society, 34(2-3), 3-23. 
This paper (post-print) has been accepted for publication in The Sociological Review. Edited, revised and typeset version of this paper will be published in The Sociological Review, vol. 67(6) by Sage, All rights reserved. (C Sage, 2019

Clarke, B. (2017). Rethinking Gaia: Stengers, Latour, Margulis. Theory, Culture \& Society, 34(4), 3-26.

Coole, D., \& Frost, S. (Eds.) (2010). New materialisms: Ontology, agency, and politics. Durham, NC: Duke University Press.

Danowski, D., \& Viveiros de Castro, E. (2017). The Ends of the World. Cambridge: Polity.

de la Cadena, M. (2015). Earth Beings: Ecologies of practice across Andean worlds. Durham, NC: Duke University Press.

Deleuze, G., \& Guattari, F. (1987). A thousand plateaus: Capitalism and schizophrenia. Minneapolis \& London: University of Minnesota Press.

Fleck, L. (1979 [1935]). Genesis and development of a scientific fact. Chicago: The University of Chicago Press.

Guattari, F. (1989). The three ecologies. New formations, 8, 131-147.

Haraway, D. (2016). Staying with the trouble: Making kin in the Chthulucene. Durham, NC: Duke University Press.

Harman, G. (2015). Bruno Latour: Reassembling the political. London: Pluto Press. 
This paper (post-print) has been accepted for publication in The Sociological Review. Edited, revised and typeset version of this paper will be published in The Sociological Review, vol. 67(6) by Sage, All rights reserved. (C Sage, 2019

Jensen, C. B. (2007). Infrastructural fractals: Re-visiting the micro-macro distinction in social theory. Environment and Planning D, 25(5), 832-50.

Jensen, C. B. (2012). Anthropology as a following science: Humanity and sociality in continuous variation. NatureCultures, 1(1), 1-24.

Jensen, C. B. (2015). Experimenting with political matters: Environmental infrastructures and ontological transformations. Distinktion: Scandinavian Journal of Social Theory, 16(1), 17-30.

Jensen, C. B., \& Blok, A. (2013). Techno-animism in Japan: Shinto cosmograms, actornetwork theory, and the enabling powers of non-human agencies. Theory, Culture \& Society, 30(2), 84-115.

Latour, B. (1988). The pasteurization of France. Cambridge, MA: Harvard University Press.

Latour, B. (2000). When things strike back: a possible contribution of 'science studies' to the social sciences. British Journal of Sociology, 51(1), 107-123.

Latour, B. (2004). Politics of nature: How to bring the sciences into democracy. Cambridge, MA: Harvard University Press.

Latour, B. (2017). Facing Gaia: Eight lectures on the new climatic regime. Cambridge: Polity Press. 
This paper (post-print) has been accepted for publication in The Sociological Review. Edited, revised and typeset version of this paper will be published in The Sociological Review, vol. 67(6) by Sage, All rights reserved. (C Sage, 2019

Malm, A., \& Hornborg, A. (2014). The geology of mankind: A critique of the Anthropocene narrative. The anthropocene review, 1(1), 62-69.

Meillassoux, Q. (2008). After finitude: An essay on the necessity of contingency. New York: Continuum.

Moore, J. W. (2015). Capitalism in the web of life: Ecology and the accumulation of capital. London: Verso.

Pignarre, P., \& Stengers, I. (2011). Capitalist sorcery: Breaking the spell. Basingstoke: Palgrave Macmillan.

Rockström, J. et al. (2009). A safe operating space for humanity. Nature, 461, 24 September, $472-5$.

Savransky, M. (2016). The adventure of relevance: An ethics of social inquiry. Basingstoke: Palgrave Macmillan.

Stengers, I. (2000). The invention of modern science. Minneapolis and London: University of Minnesota Press.

Stengers, I. (2005). Introductory notes on an ecology of practices. Cultural Studies Review, 11(1), 183-196. 
This paper (post-print) has been accepted for publication in The Sociological Review. Edited, revised and typeset version of this paper will be published in The Sociological Review, vol. 67(6) by Sage, All rights reserved. (c) Sage, 2019

Stengers, I. (2014). Speculative Philosophy and the Art of Dramatization. In R. Faber, \& A. Goffey (Eds.), The Allure of Things (pp. 188-217). London and New York: Bloomsbury.

Stengers, I. (2015a). Accepting the reality of Gaia: A fundamental shift? In C. Hamilton, C. Bonneuil, \& F. Gemenne (Eds.), The Anthropocene and the Global Environmental Crisis: Rethinking modernity in a new epoch (pp. 134-144). Milton Park and New York: Routledge.

Stengers, I. (2015b). In catastrophic times: Resisting the coming barbarism. Ann Arbor, MI: Open Humanities Press.

Stengers, I. (2017). Autonomy and the intrusion of Gaia. South Atlantic Quarterly, 116(2), 381-400.

Stengers, I., Davis, H., \& Turpin, E. (2013). Matters of cosmopolitics: On the provocations of Gaia. In E. Turpin (Ed.) Architecture in the Anthropocene: Encounters among design, deep time, science and philosophy. London: Open Humanities Press.

Stone, C. D. (1996 [1974]). Should trees have standing? And other essays on law, morals, and the environment. Dobbs Ferry, NY: Oceana Publications.

Tsing, A. L. (2012). On Nonscalability: The Living World is Not Amenable to Precisionnested Scales. Common Knowledge, 18(3), 505-524. 
This paper (post-print) has been accepted for publication in The Sociological Review. Edited, revised and typeset version of this paper will be published in The Sociological Review, vol. 67(6) by Sage, All rights reserved. (c) Sage, 2019

Tsing, A. L. (2015). The mushroom at the end of the world: On the possibility of life in capitalist ruins. Princeton: Princeton University Press.

Wark, M. (2015). Molecular red: Theory for the Anthropocene. New York: Verso.

Yusoff, K. (2013). Geologic Life: Prehistory, Climate, Futures in the Anthropocene. Environment and Planning D, 31(5), 779-795. 